Supplemental Information

\title{
DNA Looping Mediated by Site-Specific SfiI-DNA Interactions
}

\author{
Sridhar Vemulapalli ${ }^{1}$, Mohtadin Hashemi ${ }^{1}$, Anatoly B. Kolomeisky ${ }^{2 *}$, and Yuri L. \\ Lyubchenko $^{1 *}$ \\ ${ }^{1}$ Department of Pharmaceutical Sciences, College of Pharmacy, University of Nebraska Medical \\ Center, 986025 Nebraska Medical Center, Omaha, NE 68198-6025, USA \\ ${ }^{2}$ Department of Chemistry-MS60, 6100 Main Street, Houston, TX 77005-1892, USA
}

*Corresponding authors: Yuri L. Lyubchenko: ylyubchenko@unmc.edu and Anatoly Kolomeisky: tolya@rice.edu 
Table S1. Yield of looped SfiI-DNA complexes on three-SfiI-site DNA construct at 4, 25, and $50{ }^{\circ} \mathrm{C}$. Yield reflects the yield for all looped complexes, regardless of loop size.

\begin{tabular}{ccccc}
\hline Temperature $\left[{ }^{\circ} \mathbf{C}\right]$ & $\operatorname{Exp~1~}$ & $\operatorname{Exp~2~}$ & $\operatorname{Exp~3~}$ & Average* $^{*}$ \\
\hline 4 & 37.2 & 38.2 & 39.9 & $38.4( \pm 1.12)$ \\
25 & 56.1 & 57.5 & 59.3 & $57.6( \pm 1.30)$ \\
50 & 48.6 & 48.9 & 49.7 & $49.1( \pm 0.46)$ \\
\hline
\end{tabular}

$*_{ \pm}$standard deviation. 
Table S2. Statistical comparison of loop distribution on three-SfiI-site DNA construct using nonparametric Kolmogorov-Smirnov test. Significant difference indicated by: * at $\mathrm{p}<0.05, * *$ at $\mathrm{p}$ $<0.01$, and $* * *$ at $\mathrm{p}<0.001$.

\begin{tabular}{|c|c|c|c|c|c|c|c|c|c|c|}
\hline & & \multicolumn{3}{|c|}{ Short } & \multicolumn{3}{|c|}{ Medium } & \multicolumn{3}{|c|}{ Long } \\
\hline & $\mathbf{T}\left({ }^{\circ} \mathbf{C}\right)$ & 4 & 25 & 50 & 4 & 25 & 50 & 4 & 25 & 50 \\
\hline \multirow{3}{*}{ Short } & 4 & & $*$ & $* *$ & & & & & & \\
\hline & 25 & $*$ & & $* * *$ & & & & & & \\
\hline & 50 & $* *$ & $* * *$ & & & & & & & \\
\hline \multirow{3}{*}{ Medium } & 4 & & & & & $* * *$ & $* * *$ & & & \\
\hline & 25 & & & & *** & & $* * *$ & & & \\
\hline & 50 & & & & $* * *$ & $* * *$ & & & & \\
\hline \multirow{3}{*}{ Long } & 4 & & & & & & & & $* *$ & $* * *$ \\
\hline & 25 & & & & & & & $* *$ & & $* * *$ \\
\hline & 50 & & & & & & & $* * *$ & $* * *$ & \\
\hline
\end{tabular}


Restriction digest reaction was performed to confirm the activity of the enzyme and presence of three restriction sites on the purified DNA obtained from the PCR of pUC19 plasmid. A two-trail reaction was performed. The reaction mixture for each trail consisted of $4 \mu \mathrm{lof} 86 \mathrm{ng} / \mu 13$-site DNA construct, $0.5 \mu 1$ of SfiI enzyme, $2 \mu 1$ 10x NEB buffer, and nuclease free water to final volume of $20 \mu \mathrm{l}$. The reaction mixture was incubated at $50^{\circ} \mathrm{C}$ for $1 \mathrm{hr}$. A $0.7 \%$ agarose gel was used to characterize the reaction. The entire reaction volume was run on the gel. The gel was run at $250 \mathrm{~mA}$ for $4 \mathrm{hrs}$. ImageQuant ${ }^{\mathrm{TM}}$ LAS 4000 (GE Healthcare, Chicago, IL) was used to image the gel. Multiple bands at the molecular weights corresponding to the possible loop sizes of 254 bp, $532 \mathrm{bp}$, and $786 \mathrm{bp}$ as well as an additional band around $100 \mathrm{bp}$ were expected and identified on the gel.

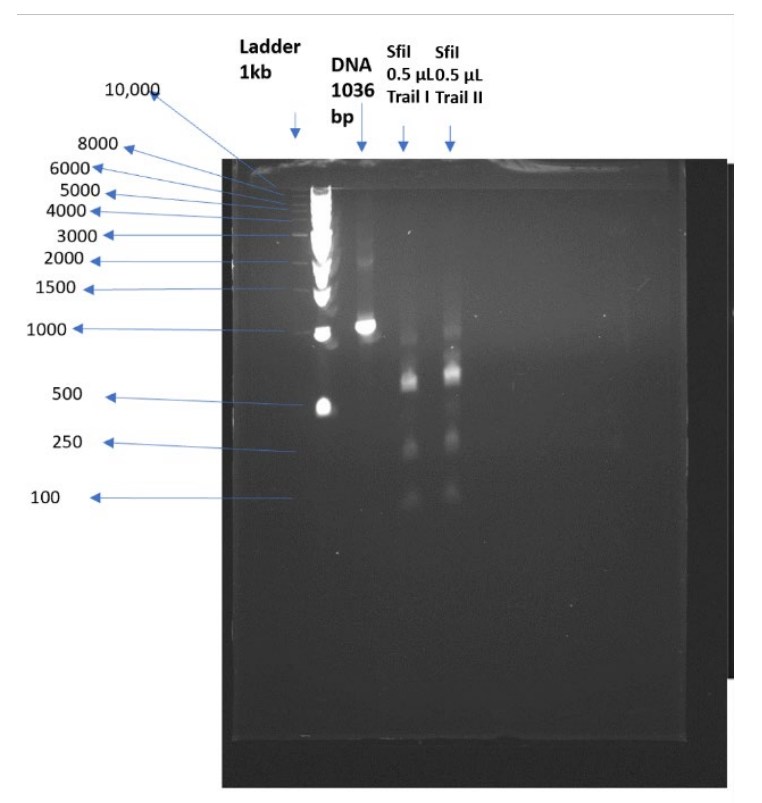

Figure S1. The restriction digestion gel of DNA with three SfiI sites: Multiple bands around 100 bp, $250 \mathrm{bp}, 800 \mathrm{bp}$, and a light band around $500 \mathrm{bp}$ can be seen on the gel image. 
DNA sequencing of three-SfiI-site construct.

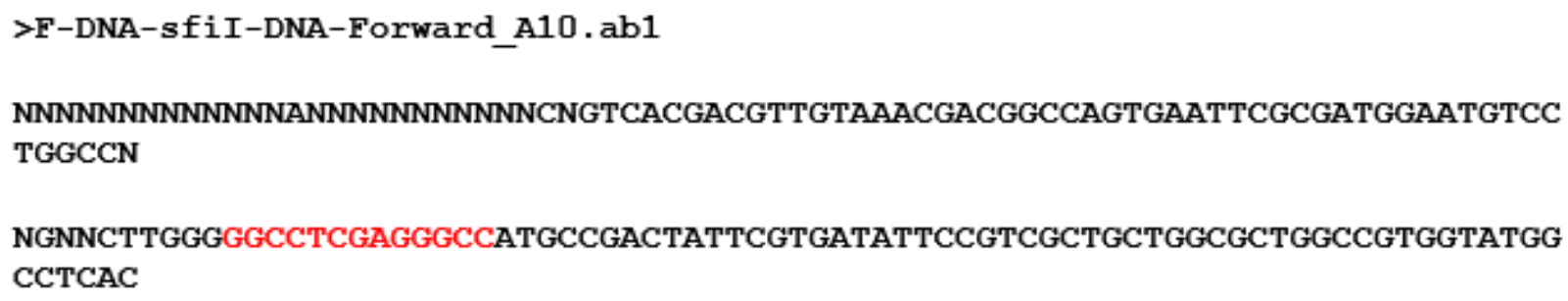

Figure S2. Sequencing data of three-SfiI-site DNA construct. The SfiI sites are highlighted in red; the distance between the three restriction sites were similar to the designed construct. Sequencing was performed by UNMC Genomics Core Facility. 
Single-SfiI-site DNA construct.

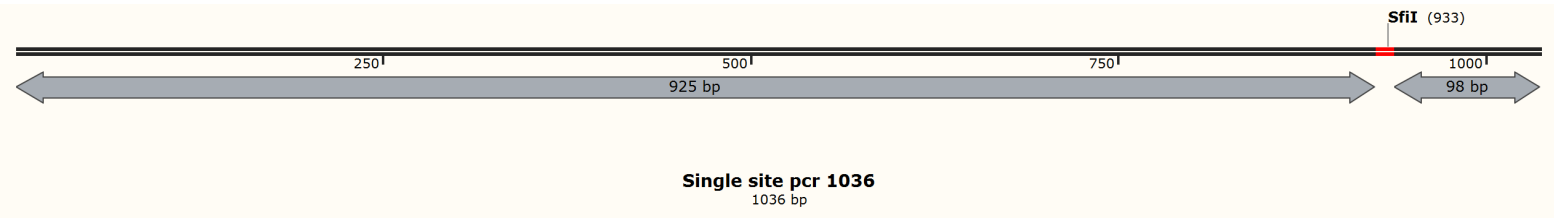

Figure S3. Schematic of the single-SfiI-site DNA construct used in this study, generated using SnapGene (version 5.2, GSL Biotech LLC, Chicago, IL). The SfiI site is represented as a red bar. The arm lengths are given in base pairs. 


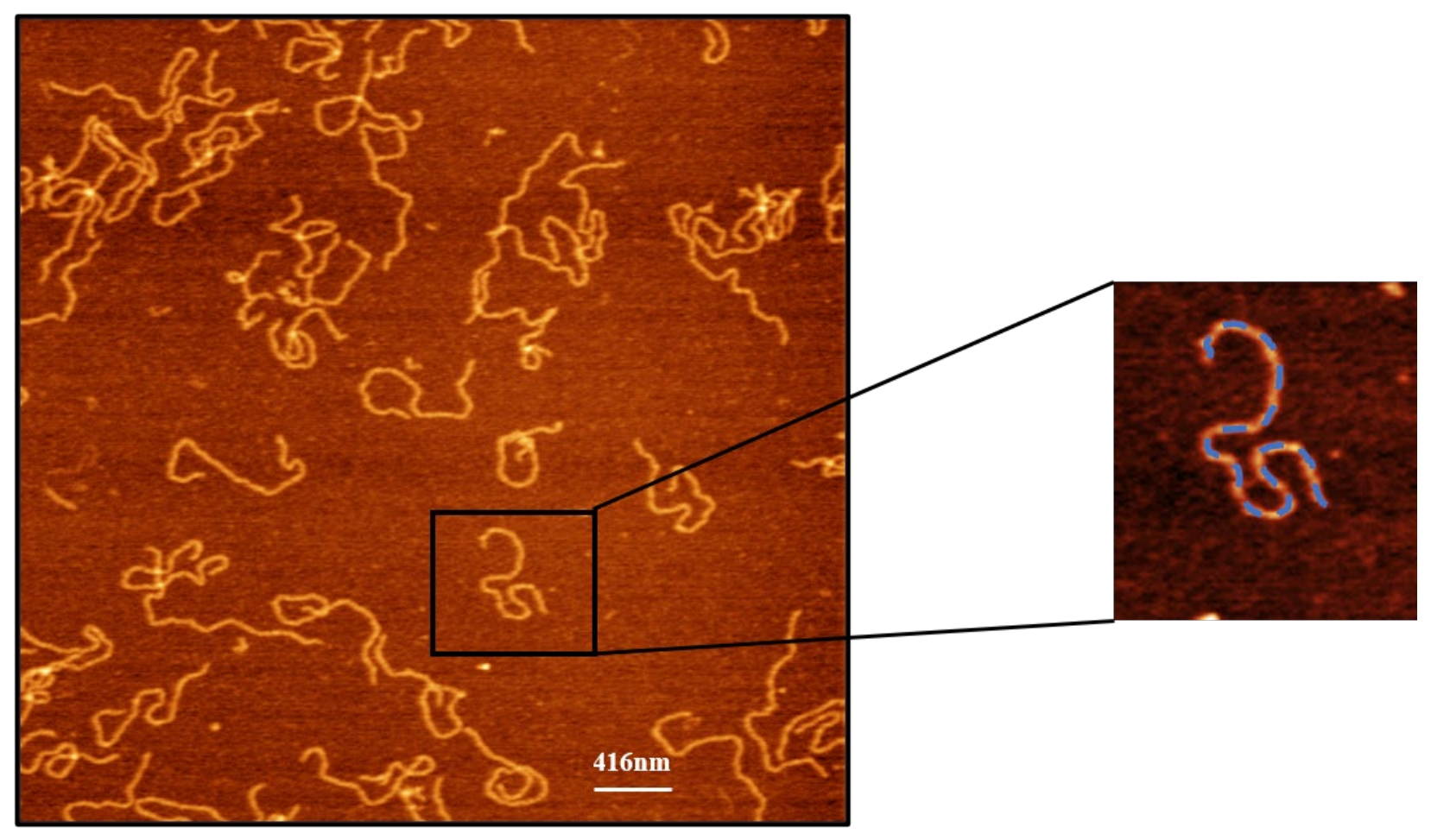

Figure S4. DNA contour length measurement. A typical 1x1 $\mu \mathrm{m}$ AFM image of free three-SfiIsite DNA. The zoomed insert shows the trace (continuous dotted line from one end to the other) used to measure the contour length of the DNA. Same procedure was followed to measure the DNA length of single-SfiI-site DNA construct. FemtoScan software (Advanced Technologies Center, Moscow, Russia) was used to perform the measurements. 
The DNA contour length for the 3-SfiI-site DNA construct.

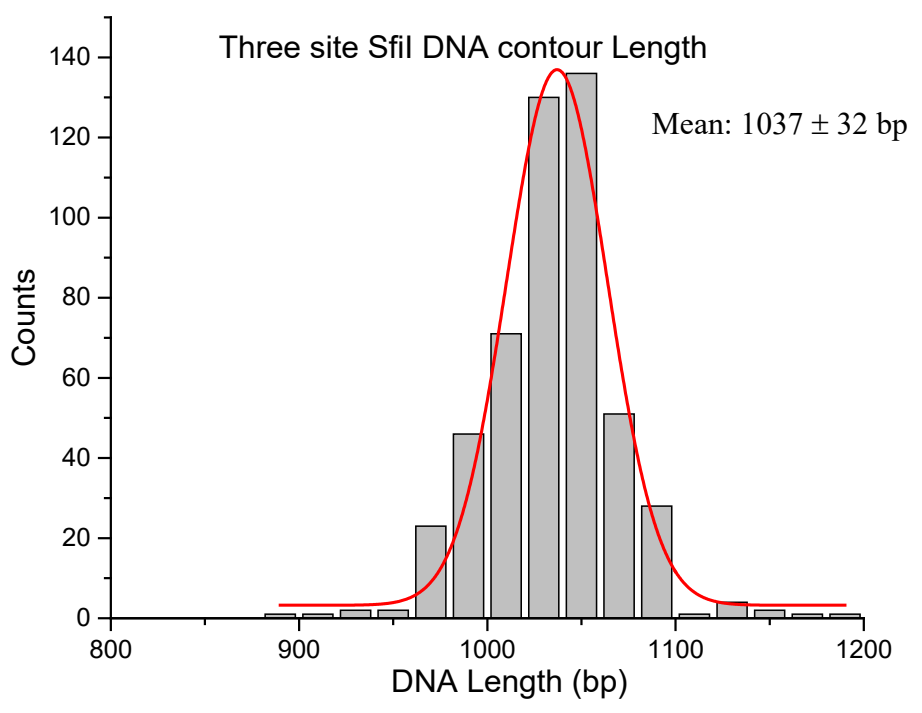

Figure S5. Statistical analysis of DNA contour length for free three-SfiI-site DNA $(\mathrm{N}=500)$. A single peak Gaussian was fit to the histogram using a bin size of $20 \mathrm{bp}$, yielding a peak at $1037 \pm$ $32 \mathrm{bp}$ (SD). The conversion factor was obtained by dividing the mean length in nanometers with the total length of DNA (1036 bp). Statistical analysis was performed using OriginPro (Origin Labs, Northampton, MA). 
DNA contour length for the single-SfiI-site construct.

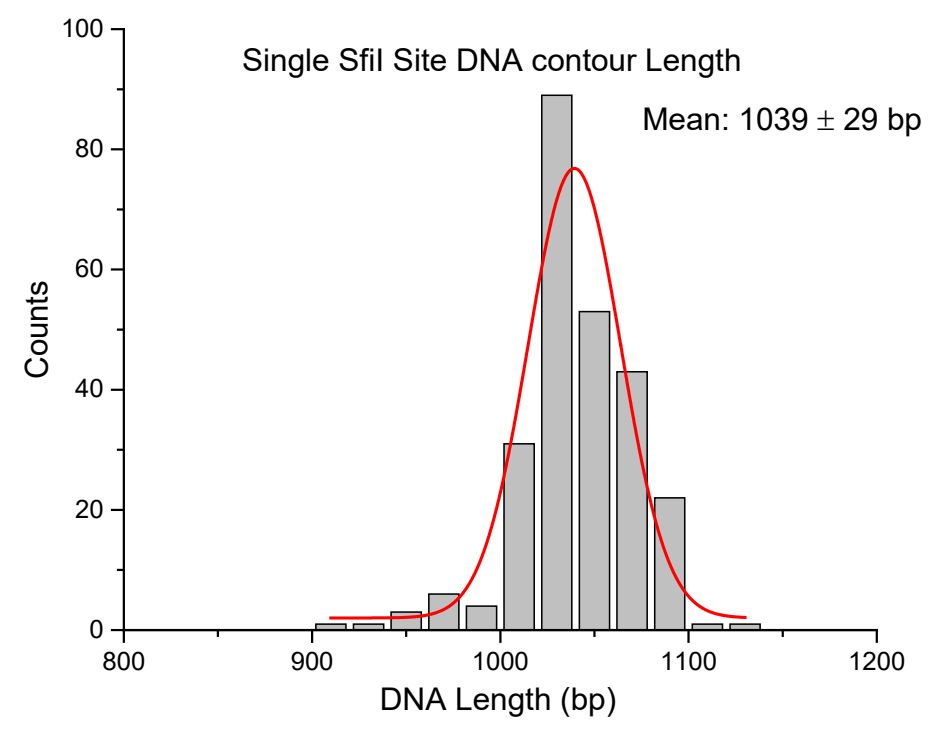

Figure S6. Statistical analysis of DNA contour length for free single-SfiI-site DNA $(\mathrm{N}=255)$. A Gaussian was fit to the histogram using a bin size of $20 \mathrm{bp}$, which gives a peak at $1039 \pm 29 \mathrm{bp}$ (SD). The conversion factor was obtained by dividing the mean length in nanometers with the total length of DNA (1036 bp). The conversion factor was 0.339 . Statistical analysis was performed using OriginPro (Origin Labs, Northampton, MA). 
$\underline{\text { SfiI-DNA loop size measurement. }}$

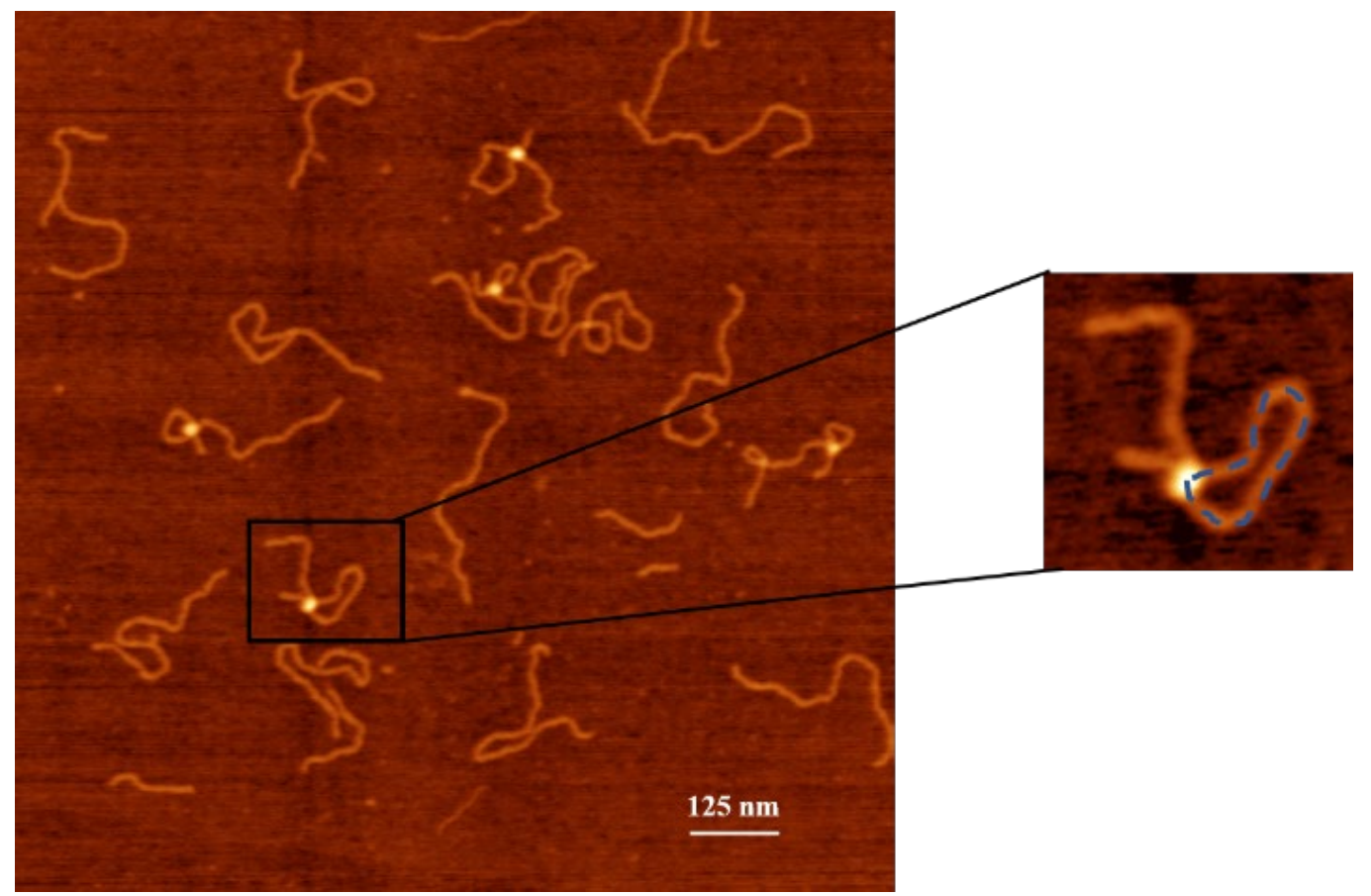

Figure S7. SfiI-DNA complex loop size measurement. A typical 1x1 $\mu \mathrm{m}$ AFM image of SfiIDNA complex on the three-SfiI-site construct. The zoomed image to the right shows the trace (dotted line in blue) along the length of the DNA loop used to perform the measurements. The different loop sizes of the DNA-Sfil complex, obtained at all three temperatures, were measured using the same procedure. FemtoScan software (Advanced Technologies Center, Moscow, Russia) was used to analyze the images. 
Proability distribution overlay of loop formation at $4{ }^{\circ} \mathrm{C}, 25^{\circ} \mathrm{C}$, and $50^{\circ} \mathrm{C}$.

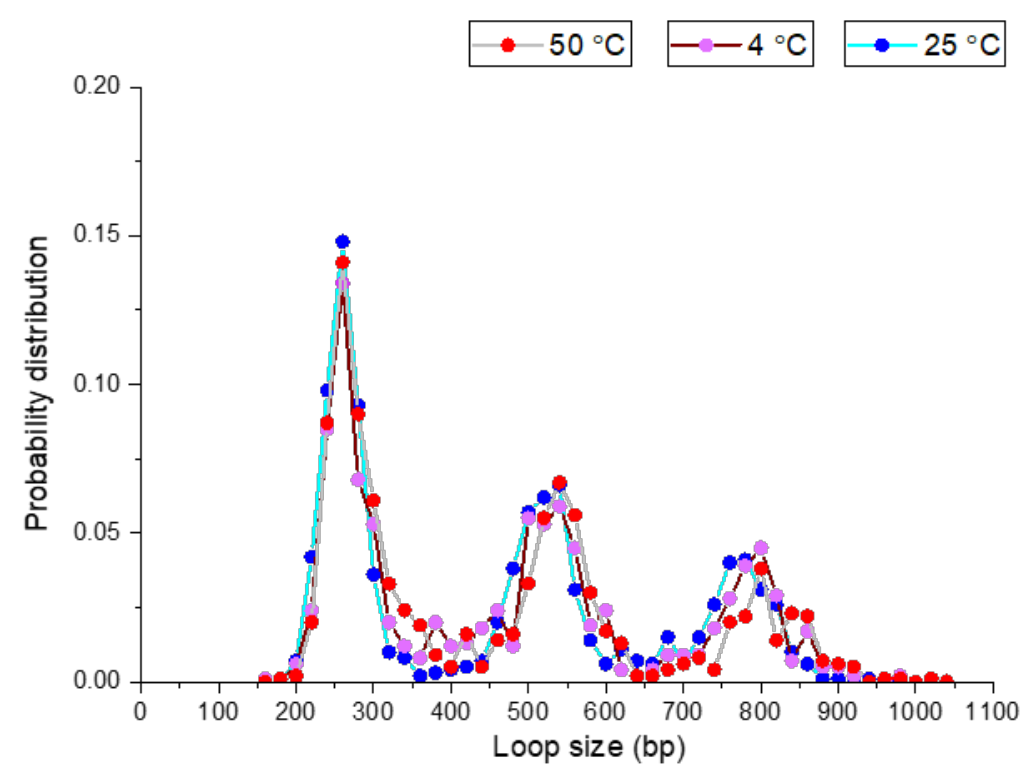

Figure S8. Probability distribution of loop formation at different temperatures: The above graph gives the probability of formation of different loops at different temperatures. Area under the curve of each distribution peak will give the relative probability of each loop size. 
Transient loops formed on single-SfiI-site DNA and SfiI position from the DNA flank.
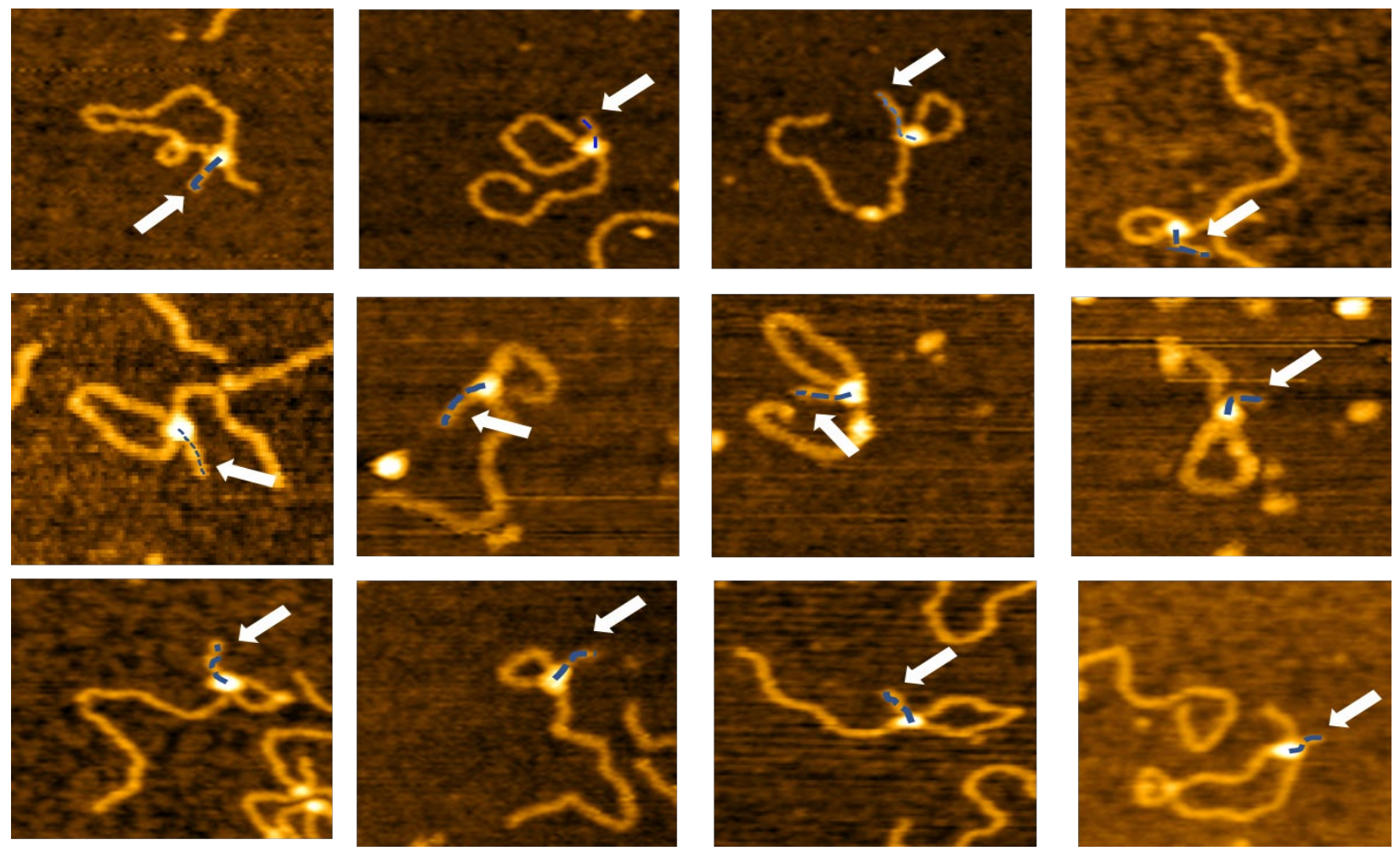

Figure S9. Transient loops of SfiI-DNA on single-SfiI-site substrate. Different loops sizes can be seen in the above gallery. The arrows indicate the flank of DNA measured to confirm the positioning of SfiI from the end of the DNA. The length was measured by tracing a line along the DNA to the center of the SfiI, as shown with the blue dotted line. 